\title{
Autoconcepto de mujeres migrantes maltratadas víctimas de violencia machista: una propuesta educativa para ayudar a recuperar el equilibrio emocional a través de la danza*
}

\author{
Selfconcept of abused migrant women victims of sexist violence: \\ An educational proposal to help recover emotional balance through dance \\ María del Carmen Vera Esteban ${ }^{a}$, María Cristina Cardona Moltóa \\ ${ }^{a}$ Instituto Universitario de Investigación de Estudios de Género, Universidad de Alicante. \\ mdcv5@alu.ua.es, cristina.cardona@ua.es
}

\begin{abstract}
RESUMEN
Este estudio analiza el autoconcepto de un grupo de mujeres maltratadas residentes en una Casa de Acogida de la provincia de Alicante, España. Su propósito fue conocer sus necesidades y delinear un plan de intervención para ayudar a recuperar el equilibrio emocional perdido. Las participantes fueron 15 mujeres migrantes víctimas de violencia machista procedentes de América del Sur, América Central, Europa del Este, Norte de África y Asia Oriental y 19 mujeres españolas sin historia de maltrato incluidas en el diseño como estrategia de comparación. Las medidas se obtuvieron mediante el Test AF5 que mide las dimensiones: (1) académico-laboral, (2) social, (3) emocional, (4) familiar y (5) física del autoconcepto. Los resultados evidenciaron que las participantes que han sufrido maltrato necesitan recuperar el equilibrio emocional a través del fortalecimiento de su concepto profesional, socioemocional, familiar y físico en base a cuyas necesidades se propone un plan de intervención para ayudar a su recuperación a través de la danza.
\end{abstract}

Palabras claves: Autoconcepto, maltrato machista, mujeres migrantes, educación, danza contemporánea.

\begin{abstract}
This study analyzes the self-concept of a group of abused women residents of a shelter in the province of Alicante, Spain. Its aim was to know their needs and provide an intervention plan to improve their emotional balance. The participants were 15 abused migrant women from South America, Central America, Eastern Europe, North Africa and East Asia and 19 Spanish women with no history of abuse included in the design as a strategy to compare the self-concept of both groups. The measures were obtained through the AF5 Self-Concept Test that measures the (1) academic-labor, (2) social, (3) emotional, (4) familiar and (5) physical dimensions. The results showed that the participants who have suffered abuse need to recover emotional balance through improvement of their professional, socioemotional, familiar and physical self-concept. Based on these findings a plan for emotional recovery through dance is proposed.
\end{abstract}

Key words: Self-concept, sexist abuse, migrant women, education, contemporary dance.

\footnotetext{
* $\quad$ Agradecimientos. Esta investigación recibió el apoyo de la Universidad de Alicante, a través de la ayuda de financiación recibida por el Vicerrectorado de Investigación al grupo "Diversidad, Educación y Género" (VIGROB-298). Las autoras agradecen, asimismo, la colaboración en el estudio de la dirección y equipo de profesionales de la Casa de Acogida y del Conservatorio Superior de Danza de Alicante, así como de las participantes, sin cuya contribución no hubiera sido posible realizarlo.
} 
Estudios Pedagógicos XLVI N 2: 421-445, 2020

AUTOCONCEPTO DE MUJERES MIGRANTES MALTRATADAS VÍCTIMAS DE VIOLENCIA MACHISTA: UNA

PROPUESTA EDUCATIVA PARA AYUDAR A RECUPERAR EL EQUILIBRIO EMOCIONAL A TRAVÉS DE LA DANZA

\section{INTRODUCCIÓN}

El presente estudio aborda la violencia y maltrato machista hacia las mujeres y su repercusión en el deterioro de su autoconcepto y bienestar psicológico. El maltrato es un problema generalizado de las sociedades modernas que urge erradicar, dado que mientras no se elimine o reduzca considerablemente estaremos lejos de haber alcanzado la igualdad real entre hombres y mujeres. Este comportamiento machista deja graves secuelas, difíciles de reparar, en la salud de las mujeres que lo sufren y también en sus hijos. Las consecuencias psicológicas y físicas, según la Organización Panamericana de la Salud (OPS, 2003), pueden ser muy variadas: (a) problemas de salud mental: estrés postraumático, depresión, angustia, fobias, estado de pánico, trastornos alimentarios, disfunción sexual, escasa autoestima, abuso de psicotrópicos; (b) comportamientos negativos: tabaquismo, abuso de alcohol y drogas, comportamientos sexuales arriesgados, inactividad física, comer en exceso; (c) afectación de la salud física: lesiones, alteraciones funcionales, salud subjetiva deficiente, discapacidad permanente, obesidad severa; (d) alteraciones en la salud reproductiva: embarazo no deseado, enfermedades de transmisión sexual/VIH, trastornos ginecológicos, abortos peligrosos, complicaciones del embarazo, abortos, bajo peso al nacer, enfermedad de inflamación pélvica; (e) trastornos crónicos: síndromes dolorosos graves, síndrome del intestino irritable, gastrointestinales, fibromialgia; (f) efectos mortales: homicidio, suicidio, efectos relacionados con VIH y enfermedad pélvica.

La mayor o menor repercusión psicológica de un suceso traumático como el maltrato en una persona depende, para Echeburúa (2004), de la vulnerabilidad psicológica, que se refiere a la precariedad de su equilibrio emocional, y de la sensibilidad o fragilidad biológica, caracterizada por un menor umbral de activación psicofisiológica. Ambos tipos de vulnerabilidad pueden acrecentar el daño psicológico de las experiencias negativas sufridas.

Dado el impacto del maltrato en las mujeres a nivel global y, al objeto de situar el problema en contexto, en este estudio se analizan las medidas propuestas por los organismos internacionales para prevenir y tratar de erradicar la violencia machista. A continuación, nos adentramos en el fenómeno de la violencia de género en España aportando información sobre la situación actual, legislación vigente y medidas sociales tomadas para ayudar a las mujeres víctimas de este tipo de comportamientos. El estudio enfatiza el deterioro psicológico y del equilibrio emocional que sufren las mujeres víctimas de maltrato y, utilizando una metodología de investigación comparada, identifica y compara su autoconcepto con el de otro grupo de mujeres sin historia de maltrato. Como recurso para la intervención se presenta la danza contemporánea como una medida potenciadora del bienestar psicológico, paliativa de los efectos negativos del maltrato por su capacidad para ayudar a recuperar el equilibrio emocional perdido.

\section{EL RECONOCIMIENTO DEL DERECHO A LA IGUALDAD POR LOS ORGANISMOS INTERNACIONALES}

La lucha por la igualdad de los derechos entre hombres y mujeres comenzó en 1945 después de la Segunda Guerra Mundial, tras la devastación internacional ocurrida, momento en el que se constituyó la Organización de las Naciones Unidas (ONU) con la finalidad de promover la cooperación internacional en asuntos de interés mundial. La mayoría de los 
51 Estados Miembros, al firmar la Carta de la ONU como documento fundacional, se comprometió a luchar por la igualdad de derechos entre mujeres y hombres, además de abogar por el desarrollo y promoción de las libertades fundamentales de todo ser humano sin distinción de raza, sexo, idioma o religión. En el seno de la ONU, se constituyó en 1946 la Comisión de la Condición Jurídica y Social de la Mujer como el primer organismo mundial con dedicación plena a la promoción de la igualdad de género y al empoderamiento de las mujeres. Su misión era supervisar la condición de los derechos de las mujeres en todo el mundo y definir los estándares internacionales sobre igualdad de género. En 1948, la Asamblea General de las Naciones Unidas, como máximo órgano deliberante, tras detectar la constante violación de los derechos humanos, proclamó la Declaración Universal de los Derechos Humanos (Naciones Unidas, 1948), compuesta de 30 artículos entre los que destacan los art. 1, 2 y 3 que inciden en el reconocimiento de la igualdad de derechos del ser humano independientemente de sus características.

En el año 1975, se celebró la Primera Conferencia Mundial sobre la Mujer de Naciones Unidas (Naciones Unidas, 1975), que tuvo lugar en México, en la que se señaló como propósito prioritario enseñar a respetar la integridad física de la mujer. Se establecieron tres objetivos principales: igualdad, desarrollo y paz, partiendo de la idea de que el cuerpo humano, tanto del hombre como de la mujer, es inviolable y el respeto por él es un elemento fundamental de la dignidad y la libertad humana. Asimismo, se declaró la década 1976-1985 como Decenio de las Naciones Unidas para las Mujeres. Durante este tiempo se llevó a cabo una profunda revisión de los derechos de las mujeres que culminó con la aprobación por la Asamblea General de las Naciones Unidas, en 1979, de la (CEDAW) (Naciones Unidas, 1979). Esta Convención definió el significado de discriminación contra las mujeres y estableció las obligaciones legales adquiridas por los países signatarios para ayudar a poner fin a la discriminación por razón de género.

(...) la expresión 'discriminación contra la mujer' denotará toda distinción, exclusión o restricción basada en el sexo que tenga por objeto o por resultado menoscabar o anular el reconocimiento, goce o ejercicio por la mujer, independientemente de su estado civil, sobre la base de la igualdad del hombre y la mujer, de los derechos humanos y las libertades fundamentales en las esferas política, económica, social, cultural y civil o en cualquier otra esfera. (Plataforma CEDAW, art. 1)

Unos años más tarde, en la Conferencia Mundial de Derechos Humanos celebrada en Viena, en junio de 1993, se dio un paso adelante al reconocer la violencia de género como una violación de los derechos humanos, lo que supuso un cambio histórico en la conceptualización de los derechos de la mujer y en la necesidad de protegerlos. Como consecuencia, la Asamblea General de las Naciones Unidas aprobó la Declaración sobre la Eliminación de la Violencia contra la Mujer (DEVAW) (Naciones Unidas, 1993), aportando así el primer referente a nivel internacional en el que se definían las diferentes formas de violencia contra las mujeres.

(...) por 'violencia contra la mujer' se entiende todo acto de violencia basado en la pertenencia al sexo femenino que tenga o pueda tener como resultado un daño o sufrimiento físico, sexual o psicológico para la mujer, así como las amenazas de tales actos, la coacción o la privación arbitraria de la libertad, tanto si se producen en la vida pública como en la vida privada (DEVAW, art. 1). 
Estudios Pedagógicos XLVI Nº 2: 421-445, 2020

AUTOCONCEPTO DE MUJERES MIGRANTES MALTRATADAS VÍCTIMAS DE VIOLENCIA MACHISTA: UNA

PROPUESTA EDUCATIVA PARA AYUDAR A RECUPERAR EL EQUILIBRIO EMOCIONAL A TRAVÉS DE LA DANZA

Finalmente, con la finalidad de acelerar la mejora de sus condiciones de vida y responder a las necesidades a las que se enfrentan las mujeres víctimas de violencia de género, los Estados Miembros optaron por crear en 2010 una entidad de las Naciones Unidas para la igualdad de género y el empoderamiento de las mujeres (ONU Mujeres). En su seno se creó el Fondo de Desarrollo de las Naciones Unidas para la Mujer (UNIFEM) con la misión de tratar de eliminar la violencia y todas las formas de discriminación en la medida de lo posible. Este Fondo se encarga de dar apoyo a entidades intergubernamentales como la Asamblea General y la Comisión sobre la Condición Jurídica y Social de la Mujer, así como de proporcionar asistencia a los Estados Miembros para conseguir implementar los estándares relativos a la igualdad con el apoyo técnico y financiero adecuado.

\section{DIMENSIONES DEL MALTRATO MACHISTA Y CONSECUENCIAS EN LAS MUJERES E HIJAS/OS VÍCTIMAS DE VIOLENCIA}

Según UNIFEM (2010), tres de cada cuatro mujeres en el mundo ha sufrido alguna vez en su vida violencia machista. Estas víctimas han sido golpeadas o insultadas de manera reiterada y abusiva por su pareja o expareja o han sufrido una agresión sexual por parte de un conocido o desconocido. Otras víctimas sufren a diario una violencia que no deja huella física, pero sí psicológica, como la que sufren las mujeres que aguantan vejaciones y humillaciones verbales de sus parejas. La violencia de género puede afectar a todas las mujeres por igual y no tiene fronteras. Alcanza a todas las edades y clases sociales, siendo el grupo de las niñas y adolescentes de edades comprendidas entre los 10 y los 19 años un grupo especialmente vulnerable tanto en el entorno familiar como escolar. Desde ONU Mujeres (2018), se estima que en el año 2017 fueron asesinadas 87.000 mujeres en el mundo, de las cuales más de la mitad lo fueron a manos de sus parejas o miembros familiares.

Lo grave de la situación es que, a pesar de lo alarmante de los datos, las políticas de igualdad no han ido acompañadas de los recursos financieros necesarios para ayudar a las víctimas. El Informe Sombra sobre la Aplicación de la CEDAW en el período 2008-2013 (Plataforma CEDAW, 2014) da cuenta de ello al señalar que la austeridad establecida por las políticas europeas no ha ayudado a soslayar el problema de la violencia, ya que los responsables políticos han dado prioridad a otros asuntos dejando en segundo plano la prevención y/o la intervención. Por añadidura, tampoco la mayoría de los gobiernos está haciendo frente al problema, pues solo un tercio de los Estados Miembros contabiliza los crímenes de violencia machista. Desde UNIFEM (2010) se les exige que terminen con esta impunidad, dado que la violencia machista en lugar de reducirse va en aumento.

La percepción de la violencia machista varía dependiendo de los diferentes países, lo cual hace difícil la prevención. Según Altamirano, miembro del Instituto Europeo para la Igualdad de Género (IEIG, 2015), en los países de Europa del Norte como Dinamarca, Suecia, o Finlandia, este tipo de violencia se comprende como un problema social, no así en Europa del Sur, en donde se suele atribuir el problema a las mujeres. La problemática se agrava si se tiene en cuenta que las víctimas no confían en las instituciones y no suelen interponer denuncias. De acuerdo con Rösslhumer, directora de Women Against Violence Europe (WAVE, 2015), sólo un tercio de las mujeres víctimas de violencia denuncian la agresión. La Agencia Europea para los Derechos Fundamentales (2014) aporta datos que indican que en la Unión Europea, en el año 2014, fueron 13 millones las mujeres que 
sufrieron violencia machista. Además, para atender a las víctimas se suelen ignorar las recomendaciones de ayuda contempladas en el Convenio de Estambul (Gallego, 2015). En el momento del estudio, solo ocho de los Estados Miembros ofrecían una línea telefónica de ayuda gratuita a las víctimas las 24 horas del día y se incumplía la ratio de una plaza por centro de acogida por cada 10.000 habitantes.

\subsection{IMPACTO DE LA VIOLENCIA MACHISTA EN EL BIENESTAR DE LAS MUJERES Y DE SUS HIJOS}

La violencia física y/o sexual contra mujeres, adolescentes y niñas afecta negativamente tanto a corto como a largo plazo y atenta contra la salud física, sexual y psicológica de las mujeres pudiendo ocasionar incluso la muerte (Organización Mundial de la Salud, OMS, 2013, 2017). Esta conducta violenta impide su plena participación en la sociedad y afecta también a las familias, comunidades y países ocasionando altos costes relacionados con gastos en atención sanitaria, servicios jurídicos, o baja productividad laboral. Sin embargo, el problema no está sólo en el gran número de mujeres que sufren la violencia de género, sino también en el trauma que pueden sufrir sus hijas e hijos, quienes directa o indirectamente se ven afectados. Según Patró y Limiñana (2005), uno de los mitos relacionados con la violencia machista es que la conducta violenta del maltratador hacia la mujer no representa un riesgo relevante para los hijos, pero nada más lejor de la realidad: ser testigos de la violencia o víctimas de ella conlleva consecuencias negativas en los hijos, tanto en su bienestar físico y psicológico, como en su posterior desarrollo social y emocional.

Se estima que entre 133 y 275 millones de niñas y niños de todo el mundo están expuestos a violencia de género (Naciones Unidas, 2006) y que en España el número de niñas/os afectados puede alcanzar la cifra de 800.000 niños (Mesa, Aisa y Letosa, 2011; Save the Children, 2012). Resulta difícil precisar el número exacto de menores expuestos a la violencia de género entre la población española. Las estadísticas inciden en datos referentes a las mujeres, no a los menores, y tampoco se refieren al tipo de maltrato que puedan estar recibiendo. Las últimas cifras publicadas correspondientes a uno de los informes estadísticos presentado por el Delegado de Gobierno para la Violencia de Género y la Secretaría General de Políticas de Igualdad (Ministerio de Igualdad, 2010) señala que el $92.20 \%$ de las mujeres que hicieron llamadas al servicio 016 manifestaron ser madres. Así mismo, el 8.60\% de las llamadas fueron realizadas por los hijos e hijas de las víctimas.

A partir de estas consideraciones se puede plantear la hipótesis de que un niño o niña expuesto a violencia de género es, probablemente, un niño o niña en situación de riesgo o desprotección. Las conductas y actos violentos del agresor se dirigen tanto hacia ellas y ellos como hacia la madre (insultos, amenazas, desvalorizaciones, maltrato activo, instrumentalización). Las agresiones pueden ocurrir, asimismo, de forma indirecta en su presencia o ausencia, pero influyen en el deterioro de los vínculos de afecto y de protección. El abanico de las posibles consecuencias y situaciones de violencia indirecta es amplio. Se podrían definir como todos aquellos que derivan de la falta de un ambiente seguro para el desarrollo del/la menor, las cuales generan determinadas respuestas por exceso o por defecto en las figuras paterna y materna. Entre los efectos indirectos más destacables se encuentra la merma en la capacidad de las víctimas (madres) para ejercer su rol materno adecuadamente y la incapacidad de los agresores, sobre todo, si son los padres, de establecer una relación afectiva con los hijos. En las madres, la falta de atención a las necesidades de sus hijos es el signo más evidente. Es la propia situación de violencia 
Estudios Pedagógicos XLVI N²: 421-445, 2020

AUTOCONCEPTO DE MUJERES MIGRANTES MALTRATADAS VÍCTIMAS DE VIOLENCIA MACHISTA: UNA

PROPUESTA EDUCATIVA PARA AYUDAR A RECUPERAR EL EQUILIBRIO EMOCIONAL A TRAVÉS DE LA DANZA

sufrida por la madre la que impide, en numerosas ocasiones, el establecimiento de vínculos en la relación materno-filial, por lo que la evaluación de tal vínculo es necesario para no culpabilizarla e intervenir adecuadamente.

\subsection{IMPACTO DE LA VIOLENCIA EN LOS PROCESOS EDUCATIVOS DE LAS/OS HIJAS/OS}

El maltrato en el núcleo familiar afecta directamente al aprendizaje de las/os niñas/os y jóvenes. Una consecuencia directa en los expuestos a la violencia es el deterioro de la autoestima, creando una imagen negativa de sí mismos, y de los demás. Según Bringiotti, (2000) la crianza en hogares en los cuales existe maltrato suele generarles desórdenes emocionales, cognitivos, conductuales y sociales. Los y las menores se muestran retraídos, inseguros, tristes, temerosos de expresar lo que quieren o de comunicar sus sentimientos. De acuerdo con Larraín y Bascuñan (2008), las consecuencias de la experiencia del maltrato se manifiestan en una serie de problemas tanto en el desarrollo como en el aprendizaje. Estos niños y niñas presentan una mayor dificultad para mantener la atención en las actividades escolares y sienten que no son tan capaces como sus iguales, lo cual les avergüenza, les causa frustración y afecta a su rendimiento académico. Además, en el entorno educativo tienden a aislarse, muestran síntomas depresivos y no suelen manifestar interés por las actividades que se realizan en el centro. Su actitud, a veces, es agitada y hostil con sus iguales o con los adultos y pueden trasladar al aula la violencia sufrida y aprendida en su entorno familiar como forma de resolver los conflictos, por lo que se deterioran sus relaciones interpersonales. Según Duong, Schwartz, Chang, Kelly y Tom (2009), existe un vínculo entre los entornos familiares hostiles, la agresión infantil y el ajuste de los niños al grupo de iguales. Las víctimas del maltrato también se caracterizan por su bajo rendimiento académico en la escuela, el cual podría estar afectado por su dificultad para permanecer atentos a las tareas escolares. Schwartz, McFadyen-Ketchum, Dodge, Pettit y Bates (1999) encontraron que la falta de atención temprana, la hiperactividad y los problemas de comportamiento son factores que originan la victimización posterior.

De acuerdo con lo anterior, las consecuencias del maltrato a las madres sobre los hijos pueden ser nefastas. Desde construir un adulto con una personalidad totalmente anulada hasta modelar a un futuro maltratador basado en el aprendizaje del modelo que vieron. De ahí la importancia de ayudar a las madres, así como a sus hijas e hijos, emocional y psicológicamente.

\subsection{VIOLENCIA MACHISTA EN ESPAÑA: LAS CASAS DE ACOGIDA COMO RECURSO DE PROTECCIÓN Y AYUDA A LAS VÍCTIMAS}

En España, la violencia de género se suele percibir como un problema de mujeres, únicamente del ámbito privado y, frecuentemente, asociado al alcoholismo (Instituto Europeo para la Igualdad de Género, IEIG, 2015). A pesar de esto, la violencia machista ha sido abordada con especial interés durante las dos últimas décadas debido, sobre todo, a una mayor concienciación de la sociedad en torno a esta terrible lacra que ha ganado en visibilidad considerablemente. Prueba de ello es la aparición frecuente en los medios de comunicación españoles de nuevos casos de violencia machista cuyo final es la muerte de la víctima, en muchos casos, en presencia de los propios hijos. Lamentablemente, es la fórmula a la que que recurren algunos hombres para dominar a las mujeres y de esta forma 
mantener sus privilegios en el ámbito familiar, ocasionando terribles daños a las mujeres y a sus hijos. Según el Instituto Nacional de la Mujer y para la Igualdad de Oportunidades (2018), el número de denuncias interpuestas por violencia de género en España alcanzó, en el año 2017, la cifra de 166.620 en el conjunto de las Comunidades Autónomas, en tanto que el número de mujeres muertas a manos de sus parejas o ex parejas ascendió a 974. El porcentaje promedio de víctimas en el período 2013 a 2018 fue de $65 \%$ españolas y 35\% extranjeras, mientras que el de los agresores fue de 67\% españoles y $33 \%$ extranjeros (Delegación del Gobierno Español para la Violencia de Género, 2019).

Con estos datos en mente, resulta incompresible que el Informe Sombra (Plataforma CEDAW, 2014) sobre la aplicación en España de la CEDAW, correspondiente al período 2008-2013, revelase que el presupuesto estatal español destinado a la lucha contra la violencia de género se recortara en un $23 \%$. Este recorte ha de sumarse al recorte del $49 \%$ en el presupuesto del Estado para igualdad y al $32 \%$ de media en las Comunidades Autónomas. La reforma de la Administración Local dejó a los ayuntamientos sin competencias en materia de igualdad, de manera que la prevención quedó todavía más desatendida al dar prioridad a otros asuntos. Estos datos explican el porqué actualmente, a pesar del respaldo de la legislación (Ley Orgánica 1/2004, de 28 de diciembre, de Medidas de Protección Integral contra la Violencia de Género), no se ha podido avanzar demasiado en materia de violencia de género.

En este contexto, los Centros de Recuperación Integral o Casas de Acogida constituyen un recurso de protección y ayuda a las víctimas. Estos centros, reconocidos en la Ley 7/2012 Integral contra la Violencia sobre la Mujer, de 23 de noviembre, de la Generalitat Valenciana, están especializados en la atención integral a mujeres víctimas de violencia machista y menores que las acompañan.

Las víctimas acceden a las Casas de Acogida a través de las gestiones de la Red de Centros Mujer 24 Horas, previa propuesta a la Dirección General de Familia y Mujer y a las direcciones territoriales correspondientes. La entrada en las Casas es complicada, ya que algunas de las mujeres llegan padeciendo el síndrome de la mujer maltratada y mostrando alteraciones psíquicas como trastorno de estrés postraumático entendido como la "aparición de síntomas característicos que sigue a la exposición a un acontecimiento estresante y extremadamente traumático en el que el individuo se ve envuelto en hechos que representan un peligro para su vida o cualquier otra amenaza para su integridad física" (Pastor Bravo, 2015, p. 210). Antes de residir en ellas, son recibidas en los Centros de Emergencia de corta estancia, en donde no pueden permanecer más de 30 días. Cumplido este plazo, las víctimas son atendidas por un equipo de psicólogas, trabajadoras sociales y educadoras que les ayudan en la gestión de documentos, solicitud de ayudas sociales y orientación/mediación laboral y/o educativa. En estas Casas pueden permanecer seis meses con posibilidad de una prórroga de seis meses más. En aquellos casos en los que se valora y estima necesario, se puede acceder a Viviendas Tuteladas en las que las mujeres y sus hijos menores con necesidades de protección pueden convivir durante un año en régimen parcial de autogestión y autonomía, facilitándoles así la integración y normalización social. Así pues, en las Casas de Acogida las víctimas reciben prestaciones de alojamiento, manutención, protección, apoyo e intervención psicosocial.

Durante la estancia en la Casa se ponen de manifiesto comportamientos negativos debido a las alteraciones emocionales con las que llegan, así como conductas ansiosas derivadas de vivencias anteriores de amenaza para la vida. Según Pastor Bravo, (2015), 
la baja autoestima y la baja iniciativa por parte de estas mujeres hacen que se hayan acostumbrado a adoptar conductas de sumisión para evitar enfrentamientos. "La violencia repetida e intermitente, entremezclada con periodos de arrepentimiento y de ternura, suscita en la mujer unas respuestas de alerta y sobresalto permanente que se acompaña de depresión y pérdida de autoestima, así como de sentimiento de culpabilidad" (p. 211).

Características comunes a las mujeres que llegan a estos centros son una situación anterior de vulnerabilidad; situación económica inestable o precaria, sin recursos para vivir independientemente, si bien su estatus educativo y socio-cultural es diverso (Vives Cases, Álvarez Dardet, Gil González, Torrubiano Domínguez, Rohlfs y Escribà Agüir, 2009); carencias afectivas; dificultad para romper con una situación de maltrato. En algunos casos, ya han vivido una relación anterior de violencia machista con otra persona, incluso, a veces, proceden de familias muy desestructuradas con antecedentes de maltrato o de abuso familiar en la niñez.

Teniendo en cuenta lo anterior, y ante la escasez de evidencia empírica sobre los beneficios psicológicos que estas mujeres obtienen a su paso por la Casa de Acogida, el propósito de este estudio fue explorar el autoconcepto en un grupo de mujeres maltratadas residente en una Casa de Acogida de la Comunidad Valenciana con la finalidad de diseñar una propuesta educativa para mejorar su bienestar psicológico, e indirectamente, el de sus hijos a través de la danza contemporánea. Restablecer y/o mejorar su bienestar psicológico es de vital importancia para ayudarles a enfrentar los retos y buscar la independencia que les permita realizar un cambio de rumbo en sus vidas. El programa puede ayudar al proceso de recuperación de las mujeres y también de sus hijos, ya que la danza es un medio de expresión de la emoción que facilita la comunicación utilizando el cuerpo como vehículo para trasmitir sentimientos y estados emocionales que no pueden ser expresados con palabras (Fux, 1976). Concretamente, los objetivos específicos del estudio fueron:

1) Examinar el autoconcepto en mujeres víctimas de maltrato machista en las facetas académico-profesional, social, emocional, familiar y física y compararlo en función de (a) la historia de maltrato y (b) la edad (menores de 30 vs mayores de 30 años).

2) Según las necesidades identificadas, esbozar un plan de intervención para ayudar a recuperar la autoestima, el equilibrio y el concepto de sí mismas a través de la danza.

\section{MÉTODO}

\subsection{CONTEXTO Y PARTICIPANTES}

El estudio se desarrolló en una de las Casas de Acogida de la ciudad de Alicante. Esta Casa ofrece residencia a mujeres maltratadas, españolas o migrantes, en situación de riesgo y/o exclusión social, las cuales pueden alojarse en el centro con sus hijos menores. Atendiendo al protocolo establecido en dicha Casa, primero, se acoge y, después, se guía hacia un proceso de empoderamiento a todas las víctimas residentes en el centro, dando gran importancia a la recuperación de la dignidad de la mujer desde un ambiente cálido y familiar que educa en el respeto hacía sí mismas y hacia los demás. Durante su estancia en la Casa, se les ofrecen las herramientas necesarias para que sean ellas mismas 
quienes marquen sus objetivos y tomen sus propias decisiones de cara a su vuelta a la normalidad. Así pues, se les ofrece ayuda especializada e individual para la adquisición de hábitos personales, maternales y de mejora de la relación con sus hijos; apoyo psicológico y actividades terapéuticas; intervención y acompañamiento sanitario; asesoramiento jurídico; inserción laboral y formación. Además, participan en actividades de convivencia, cooperación y autoayuda, así como en talleres de expresión artística y salidas culturales. En la Casa pueden alojarse temporalmente ocho mujeres y sus hijos, y prolongar la estancia seis meses más previa la valoración y aprobación por parte del centro.

Las participantes fueron un grupo de 15 mujeres migrantes víctimas de maltrato machista $(n=15)$ que convivían en la misma Casa de Acogida. Su edad oscilaba entre los 18 y 42 años con una media de 31 años $(D T=8.44)$; el $100 \%$ eran de origen extranjero. Algunas de ellas habían llegado a la Casa con sus hijos, inicialmente con el objetivo de sentirse protegidas lejos del maltrato y con la intención de comenzar una vida nueva con la ayuda proporcionada por las profesionales del centro. En el estudio participó un segundo grupo de mujeres $(n=19)$, de origen español y sin historia de maltrato, cuya edad oscilaba entre los 18 y 54 años $(M=28.63, D T=10.84)$, seleccionadas por disponibilidad del Conservatorio Superior de Danza de la misma localidad.

Un común denominador del grupo de mujeres residentes de la Casa fue que todas habían sufrido situaciones graves de maltrato provocándoles ansiedad o incluso estados de pánico. Muchas reconocían haber perdido la identidad causándoles inestabilidad emocional y, tras la pérdida, duelo por el trauma sufrido, lo cual había afectado seriamente la confianza en su persona y en los demás. Según Echeburúa (2004), el duelo puede manifestarse en forma de síntomas somáticos (pérdida de apetito, insomnio, síntomas hipocondríacos, etc.) y psicológicos (pena y dolor, fundamentalmente). También es frecuente que tengan sentimientos de culpa, sintiendo que no han hecho todo lo posible para evitar el maltrato o que no han sabido hacer feliz a su pareja. Muchas quedan marcadas de por vida por el rencor, la amargura, el desánimo, o viven sin ilusión; otras, tras una reacción psicológica intensa, hacen frente al dolor, se readaptan a la nueva situación y atienden a sus necesidades más inmediatas; e incluso otras, se sobreponen y crean proyectos de futuro ilusionantes. Muchos de estos rasgos fueron identificados en el grupo de mujeres maltratadas quienes, a pesar de lo vivido, tuvieron la valentía de enfrentar su situación y llegar a la Casa de Acogida. Los siguientes son algunos de sus testimonios:

Siento una sensación por dentro desagradable, con ojos cerrados me mareo. Me siento débil y mareada, como si mis rodillas me fallasen. Ahora no me veo capaz de poder hacer lo que hacen las demás y me siento triste también por mi debilidad, ... he llorado mucho y no quiero llorar más. (Thabata)

Tengo la mandíbula desplazada por un golpe que me dio mi padre cuando era pequeña y también tengo la mordida cruzada y los dientes completamente desplazados de su sitio. Todavía me duele al masticar algunas cosas. (Solana)

Quiero ser como era antes. Quiero pensar por mí, decidir por mí y reírme cuando yo lo necesite. Con mi segundo marido he estado privada absolutamente de todo y dejé de ser yo misma, pasé a sentirme totalmente anulada y siempre con conflictos. Quiero recuperar lo que he perdido, pero necesito solucionar mis problemas para ser feliz. (Luceilé) 


\subsection{INSTRUMENTO}

Se utilizó el Test AF5 de Autoconcepto (García y Musitu, 1999) para medir el autoconcepto de las participantes. Este test se caracteriza por su multidimensionalidad. Permite evaluar las dimensiones académico-laboral, social, emocional, familiar y física del autoconcepto mediante una escala Likert de nueve puntos. Cada dimensión se compone, a su vez, de seis ítems que representan aspectos particulares de cada componente del constructo. El autoconcepto académico-laboral, según García y Musitu (1999), se refiere a la percepción que el sujeto tiene de la calidad del desempeño de su rol, como estudiante y/o como trabajador/a, y se mide a través de los Ítems 1, 6, 11, 16, 21, 26. El autoconcepto social hace referencia a la percepción que se tiene del desempeño en las relaciones sociales (Ítems $2,7,12,17,22,27)$. El autoconcepto emocional es la percepción del estado emocional y de las respuestas a situaciones específicas, así como del grado de compromiso e implicación en la vida cotidiana; los ítems que lo componen son Ítems 3, 8, 13, 18, 23 y 28. El autoconcepto familiar se refiere a la implicación, participación e integración en el medio familiar, percepción que se valora a través de los Ítems 4, 9, 14, 19, 24 y 29. Por último, el autoconcepto físico hace referencia a la percepción del aspecto y condición física de la persona; es decir, a cómo se percibe y cuida físicamente (Ítems 5, 10, 15, 20, 25, 30). La puntuación de cada dimensión se obtuvo de la suma de la puntuación de cada uno de los ítems que la componen.

Para su uso en esta investigación, el Test AF5 fue adaptado. La escala de medición original de 0 a 99 fue reemplazada por otra de a 0 a 9 , en donde el 0 equivale a Nada de acuerdo y 9 a Muy de acuerdo. Este cambio se realizó con la intención de simplificar y obtener una respuesta más fiable de las participantes. Además, el Test AF5 fue traducido a la lengua inglesa para facilitar las respuestas de aquellas migrantes que no entendían la lengua castellana, pero sí gozaban de una buena comprensión del inglés.

\subsection{PROCEDIMIENTO}

La investigación se llevó a cabo en cuatro momentos diferenciados: (1) solicitud de permiso para acceder a la Casa de Acogida; (2) entrevista con la directora y con las profesionales de la Casa; (3) acceso al campo para primeras tomas de contacto con las participantes; y (4) administración del Test AF5 de Autoconcepto.

El contacto con la Casa de Acogida se realizó a través de la solicitud de permiso a la Dirección Territorial de Vivienda, Obras Públicas y Vertebración de Territorio de la provincia de Alicante, a quien se informó de la pretensión del estudio y de la intención de acceder a una Casa de Acogida de mujeres víctimas de violencia de género. Una vez aceptada la solicitud y conseguida la autorización de acceso, se realizó el primer contacto telefónico con la directora de la Casa de Acogida de Alicante, quien consideró oportuno realizar una primera entrevista.

En la primera cita con la directora de la Casa se informó de la finalidad del estudio y de su desarrollo. Una vez obtenido el visto bueno de la directora, se produjo una segunda entrevista con la psicóloga y la trabajadora social, quienes aportaron la información necesaria sobre las participantes y sugirieron ideas y pautas para tener una buena primera toma de contacto con el grupo de mujeres. En la conversación, se nos informó del estado emocional de las mujeres residentes carcaterizado por un bajo autoconcepto y problemas 
emocionales diversos. Por último, se acordó la fecha de acceso al campo y primer contacto con ellas.

Tras el acceso al campo, el estudio tuvo que ser reorientado. Inicialmente, el propósito era identificar sus necesidades a nivel emocional y ayudarlas a mejorar y/o recuperar su autoconcepto y equilibrio a través de la danza. Debido al poco tiempo de permanencia en la Casa de Acogida de las participantes, se tuvo que limitar el estudio, en esta primera fase, a conocerlas y empatizar con ellas, evaluar su autoconcepto y determinar el tipo de ayuda que precisaban para proceder, en una segunda fase del estudio, a la implementación del plan de ayuda y mejora de su bienestar psicológico. Las dificultades de acceso al grupo fueron múltiples: la barrera del idioma; la diferencia de edades; las ausencias por parte de las participantes a algunas de las sesiones por diversos motivos, tales como la gestión de asuntos personales, o la necesidad de atender a sus hijos por enfermedad, o la enfermedad de ellas mismas. No todas las participantes se mostraron receptivas a la hora de exponer sus vivencias, debido al estado en que cada una se encontraba y a sus convicciones culturales y/o religiosas. No obstante, tras ocho sesiones semanales de contacto y relación con ellas, se pudo convenir su participación en esta primera fase del estudio. Tras su consentimiento informado, se administró el Test AF5, a partir de cuyos resultados se esbozaría el plan de mejora del mismo. El proceso completo de evaluación tuvo una duración de dos meses, durante el cual se identificaron sus necesidades y se concretó el tipo de ayuda que se les iba a proporcionar. Debido a la salida y llegada intermitente de nuevas mujeres víctimas de maltrato al centro se procedió a administrar el test en tres momentos. El primero fue a finales de noviembre del año 2016, el segundo en enero del 2017 y el tercero a principios de febrero del mismo año.

Para realizar una comparativa del autoconcepto de mujeres víctimas y no víctimas de maltrato, se incluyó en el diseño un segundo grupo de mujeres sin historia de maltrato. Por razones de disponibilidad, se solicitó la colaboración en el estudio del Conservatorio Superior de Danza de Alicante. Obtenida la autorización pertinente del equipo directivo, se tuvo acceso a un grupo de mujeres estudiantes del Conservatorio, quienes tras su consentimiento informado, accedieron a responder al Test AF5 que fue administrado en el mes de febrero de 2017.

\subsection{ANÁLISIS DE LOS DATOS}

El análisis de los datos se llevó a cabo utilizando el paquete SPSS, versión 25. Para dar respuesta al objetivo de explorar el autoconcepto de las mujeres participantes y compararlo en función de la historia de maltrato y la edad, se calcularon estadísticos descriptivos y medidas de dispersión; seguidamente, se contrastaron las medias aritméticas de los cuatro grupos resultantes mediante la técnica análisis factorial de la varianza entre grupos (ANOVA $2 \times 2$ ), tomando como primer factor la historia de maltrato (MM vs $\mathrm{MnM})$ y como segundo factor la edad ( $<$ de $30 v s>$ de 30 años). 


\section{RESULTADOS}

\subsection{DESCRIPCIÓN Y COMPARACIÓN DEL AUTOCONCEPTO EN MUJERES MALTRATADAS Y NO MALTRATADAS SEGÚN GRUPO DE EDAD}

El análisis descriptivo y comparado por factores (suma los ítems dentro de cada dimensión) reveló que las mujeres víctimas de violencia de género tenían un concepto de sí mismas significativamente más bajo que el de las mujeres que no habían sufrido maltrato en todas sus manifestaciones: profesional $(M=41.67 v s . M=48.95 ; p<.01)$, social $(M=37.07 v s$. $M=43.32 ; p>.05)$, emocional $(M=36.33$ vs. $M=26.42 ; p<.05)$, familiar $(M=31.53 v s$. $M=37.11 ; p<.01)$ y física $(M=31.00 v s . M=42.95 ; p<.01)$ (véase Figura 1$)$. La edad, sin embargo, no influía en el autoconcepto, ni ésta en interacción con el maltrato. Es decir, que tanto en las mujeres mayores como en las menores de 30 años, el autoconcepto considerado conjuntamente en todas sus dimensiones era más bajo en las que habían sufrido maltrato que en las que no lo habían sufrido.

Figura 1. Autoconcepto en mujeres víctimas vs no víctimas de violencia machista

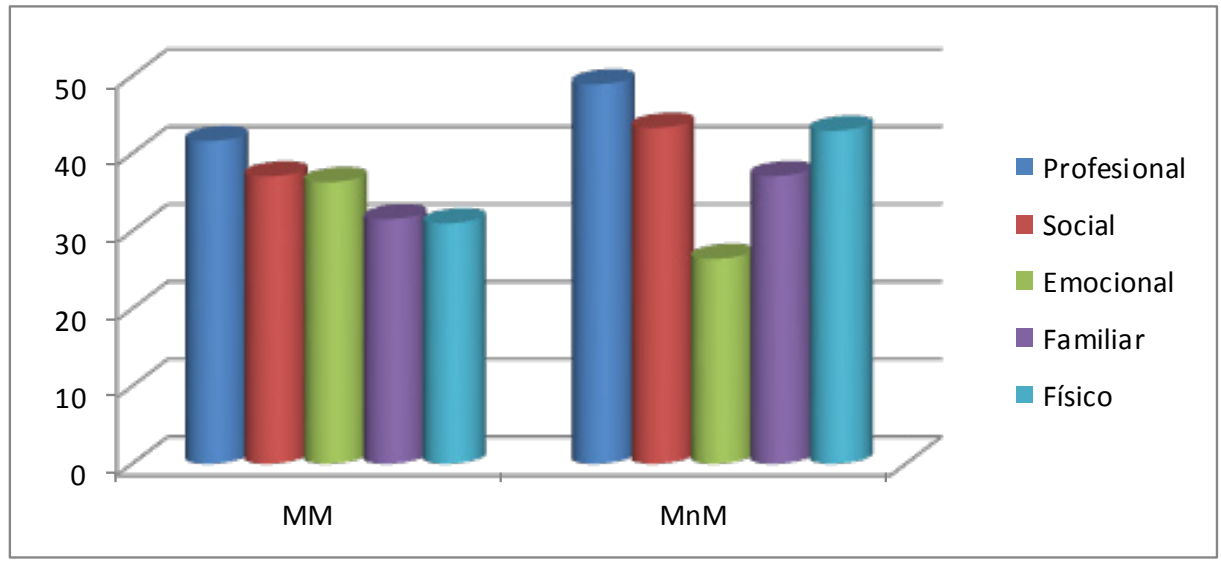

El análisis y valoración de los resultados por ítems dentro de cada dimensión vino a corroborar igualmente que la historia de maltrato influye en el autoconcepto de las mujeres, pero no la edad ni la interacción de ésta con la historia de maltrato.

\section{a) Dimensión profesional}

El maltrato influye en el autoconcepto académico-laboral de las mujeres que han sufrido violencia machista $(p<.01)$. Como puede apreciarse en la Tabla 1, el efecto principal del factor historia de maltrato resultó estadísticamente significativo en tres de los componentes del autoconcepto académico-laboral, de forma que las mujeres que habían sido maltratadas valoraban su desempeño profesional (Ítem 1) menos positivamente que las no maltratadas $(M=5.87$ vs. $M=7.79 ; F=9.79, p=.004)$, percibían que sus superiores las consideraban 
AUTOCONCEPTO DE MUJERES MIGRANTES MALTRATADAS VÍCTIMAS DE VIOLENCIA MACHISTA: UNA PROPUESTA EDUCATIVA PARA AYUDAR A RECUPERAR EL EQUILIBRIO EMOCIONAL A TRAVÉS DE LA DANZA

peor trabajadoras (Ítem 6), $M=6.47$ vs. $M=8.21 ; F=6.90, p=.013$ ), y se sentían menos estimadas por sus superiores (Ítem 16) que las mujeres no maltratadas $(M=6.60 \mathrm{vs} . M=$ $8.00 ; F=6.06, p=.020)$.

Tabla 1. Dimensión profesional del auto-concepto según historia de maltrato y grupo de edad: comparación de medias por ítem (ANOVA 2 x 2)

\begin{tabular}{|c|c|c|c|c|c|c|c|c|c|c|}
\hline \multirow[b]{2}{*}{ Profesional } & \multicolumn{2}{|c|}{ Total } & \multicolumn{2}{|c|}{ Maltratadas } & \multicolumn{2}{|c|}{ No maltratadas } & \multirow[b]{2}{*}{$F V$} & \multirow[b]{2}{*}{$F$} & \multirow[b]{2}{*}{$p$} & \multirow[b]{2}{*}{ Eta } \\
\hline & $M$ & $D T$ & $M$ & $D T$ & $M$ & $D T$ & & & & \\
\hline \multicolumn{11}{|c|}{$\begin{array}{l}\text { 1. Hago bien los trabajos } \\
\text { profesionales }\end{array}$} \\
\hline Menores de 30 & 7.05 & 1.91 & 5.67 & 2.81 & 7.64 & 1.01 & $M$ & 9.79 & $.004 *$ & .246 \\
\hline Mayores de 30 & 6.79 & 2.16 & 6.00 & 2.35 & 8.20 & 0.45 & $\mathrm{E}$ & 0.45 & .510 & .015 \\
\hline Total & 6.94 & 1.98 & 5.87 & 2.45 & 7.79 & 0.92 & $M \times E$ & 0.03 & .868 & .001 \\
\hline \multicolumn{11}{|c|}{$\begin{array}{l}\text { 6. Mis jefes me consideran } \\
\text { buena trabajadora }\end{array}$} \\
\hline Menores de 30 & 7.55 & 1.85 & 6.00 & 2.83 & 8.21 & 0.58 & $\mathrm{M}$ & 6.90 & $.013^{*}$ & .187 \\
\hline Mayores de 30 & 7.29 & 2.27 & 6.78 & 2.73 & 8.20 & 0.45 & $\mathrm{E}$ & 0.30 & .585 & .010 \\
\hline Total & 7.44 & 2.00 & 6.47 & 2.70 & 8.21 & 0.54 & $M \times E$ & 0.33 & .572 & .011 \\
\hline \multicolumn{11}{|c|}{$\begin{array}{l}\text { 11. Trabajo mucho en el } \\
\text { lugar de trabajo }\end{array}$} \\
\hline Menores de 30 & 7.95 & 1.76 & 7.00 & 3.03 & 8.36 & 0.63 & $\mathrm{M}$ & 1.36 & .252 & .043 \\
\hline Mayores de 30 & 8.29 & 0.83 & 8.33 & 1.00 & 8.20 & 0.45 & $\mathrm{E}$ & 1.26 & .271 & .040 \\
\hline Total & 8.09 & 1.44 & 7.80 & 2.08 & 8.32 & 0.58 & $M \times E$ & 2.02 & .165 & .063 \\
\hline \multicolumn{11}{|c|}{$\begin{array}{l}\text { 16. Mis superiores me } \\
\text { estiman }\end{array}$} \\
\hline Menores de 30 & 7.50 & 1.88 & 6.17 & 2.93 & 8.07 & 0.83 & M & 6.06 & $.020^{*}$ & .168 \\
\hline Mayores de 30 & 7.21 & 1.31 & 6.89 & 1.45 & 7.80 & 0.84 & $\mathrm{E}$ & 0.16 & .696 & .005 \\
\hline Total & 7.38 & 1.65 & 6.60 & 2.10 & 8.00 & 0.82 & $M \times E$ & 0.76 & .392 & .025 \\
\hline \multicolumn{11}{|l|}{$\begin{array}{l}\text { 21. Soy una buena } \\
\text { trabajadora }\end{array}$} \\
\hline Menores de 30 & 8.40 & 0.99 & 8.00 & 1.55 & 8.57 & 0.65 & $\mathrm{M}$ & 2.32 & .138 & .072 \\
\hline Mayores de 30 & 8.14 & 1.88 & 7.78 & 2.28 & 8.80 & 0.45 & $\mathrm{E}$ & 0.00 & .995 & .000 \\
\hline Total & 8.29 & 1.40 & 7.87 & 1.96 & 8.63 & 0.60 & $M \times E$ & 0.19 & .670 & .006 \\
\hline \multicolumn{11}{|c|}{$\begin{array}{l}26 . \quad \text { Mis jefes me } \\
\text { consideran inteligente y } \\
\text { trabajadora }\end{array}$} \\
\hline Menores de 30 & 7.55 & 1.99 & 6.50 & 3.27 & 8.00 & 0.96 & $\mathrm{M}$ & 2.82 & .103 & .086 \\
\hline Mayores de 30 & 7.64 & 1.15 & 7.44 & 1.24 & 8.00 & 1.00 & $\mathrm{E}$ & 0.60 & .446 & .019 \\
\hline Total & 7.59 & 1.67 & 7.07 & 2.20 & 8.00 & 0.94 & $M \times E$ & 0.60 & .446 & .019 \\
\hline
\end{tabular}

Rango escala 0-9 (Mín. 0, Máx. 9, punto medio 5.00); $\mathrm{M}=$ Maltrato; $\mathrm{E}=$ Edad; $\mathrm{M}$ x E = Maltrato x Edad; FV = Fuentes de variación; $g l=3,30 ; *$ Significativa al $5 \%$ o superior. 
Estudios Pedagógicos XLVI Nº 2: 421-445, 2020

AUTOCONCEPTO DE MUJERES MIGRANTES MALTRATADAS VÍCTIMAS DE VIOLENCIA MACHISTA: UNA

PROPUESTA EDUCATIVA PARA AYUDAR A RECUPERAR EL EQUILIBRIO EMOCIONAL A TRAVÉS DE LA DANZA

Por el contrario, el efecto principal de la edad no alcanzó significación estadística $(p>.05)$ en ninguno de los aspectos del autoconcepto académico-laboral considerados, datos que indican que éste no se halla influido por la edad (víctimas mayores o menores de 30 años). El efecto de la interacción (Maltrado x Edad) tampoco resultó estadísticamente significativo, resultado que contribuye a reafirmar que tanto en las mujeres con historia de maltrato como sin él, el autoconcepto académico-laboral no se veía afectado por la edad.

\section{b) Dimensión social}

Según puede apreciarse en las medias aritméticas y los contrastes de medias por ítems contenidas en las Tabla 2, la historia de maltrato no afecta en gran medida a las relaciones sociales de las mujeres. Según indican las medias correspondientes al Ítem 27, el maltrato influye en el mantenimiento de vínculos de amistad, datos que sugieren que las mujeres que han sufrido maltrato tienen menos amigos $(M=5.00, D T=2.33)$ que las que no lo han sufrido $(M=6.84, D T=1.61)$, siendo este efecto estadísticamente significativo $(F=6.16$, $p=.019)$. Sin embargo, la historia de maltrato no parece afectar a la facilidad $(p>.05)$ o dificultad $(p>.05)$ con la que hacen amigos (Ítems 2 y 12), como tampoco a la percepción que tienen sobre ellas mismas como personas amigables $(p>.05)$.

Tabla 2. Dimensión social del auto-concepto según historia de maltrato y grupo de edad: comparación de medias por ítem (ANOVA 2 x 2)

\begin{tabular}{|c|c|c|c|c|c|c|c|c|c|c|}
\hline \multirow[b]{2}{*}{ Social } & \multicolumn{2}{|c|}{ Total } & \multicolumn{2}{|c|}{ Maltratadas } & \multicolumn{2}{|c|}{ No maltratadas } & \multirow[b]{2}{*}{$F V$} & \multirow[b]{2}{*}{$\boldsymbol{F}$} & \multirow[b]{2}{*}{$p$} & \multirow[b]{2}{*}{ Eta } \\
\hline & $M$ & $D T$ & $M$ & $D T$ & $M$ & $D T$ & & & & \\
\hline \multicolumn{11}{|c|}{ 2. Hago fácilmente amigos } \\
\hline Menores de 30 & 7.45 & 1.61 & 6.83 & 2.32 & 7.71 & 1.20 & M & 2.17 & .151 & .067 \\
\hline Mayores de 30 & 6.50 & 2.65 & 6.00 & 3.20 & 7.40 & 0.89 & $\mathrm{E}$ & 0.55 & .464 & .018 \\
\hline Total & 7.06 & 2.12 & 6.33 & 2.82 & 7.63 & 1.12 & $M \times E$ & 0.11 & .740 & .004 \\
\hline \multicolumn{11}{|l|}{$\begin{array}{l}\text { 7. Soy una persona } \\
\text { amigable }\end{array}$} \\
\hline Menores de 30 & 7.95 & 1.85 & 7.17 & 3.13 & 8.29 & 0.91 & $\mathrm{M}$ & 0.74 & .395 & .024 \\
\hline Mayores de 30 & 8.07 & 1.07 & 8.11 & 1.27 & 8.00 & 0.71 & $\mathrm{E}$ & 0.32 & .577 & .010 \\
\hline Total & 8.00 & 1.56 & 7.73 & 2.15 & 8.21 & 0.86 & $M \times E$ & 1.11 & .301 & .036 \\
\hline \multicolumn{11}{|c|}{$\begin{array}{l}\text { 12. Es difícil para mi hacer } \\
\text { amigos }\end{array}$} \\
\hline Menores de 30 & 6.70 & 2.60 & 6.67 & 2.94 & 6.71 & 2.56 & $\mathrm{M}$ & 0.49 & .448 & .016 \\
\hline Mayores de 30 & 5.71 & 2.81 & 5.22 & 2.86 & 6.60 & 2.79 & $\mathrm{E}$ & 0.59 & .448 & .019 \\
\hline Total & 6.29 & 2.69 & 5.80 & 2.88 & 6.68 & 2.54 & $M \times E$ & 0.43 & .517 & .014 \\
\hline \multicolumn{11}{|c|}{$\begin{array}{l}\text { 17. Soy una persona } \\
\text { alegre }\end{array}$} \\
\hline Menores de 30 & 7.90 & 1.77 & 7.17 & 3.13 & 8.21 & 0.70 & $\mathrm{M}$ & 1.46 & .236 & .046 \\
\hline Mayores de 30 & 7.36 & 2.13 & 7.11 & 2.62 & 7.80 & 0.84 & $\mathrm{E}$ & 0.11 & .746 & .004 \\
\hline Total & 7.68 & 1.92 & 7.13 & 2.72 & 8.11 & 0.74 & $\mathrm{M} \times \mathrm{E}$ & 0.06 & .805 & .002 \\
\hline
\end{tabular}




\begin{tabular}{|l|c|c|c|c|c|c|c|c|c|c|}
\hline $\begin{array}{l}\text { 22. Me cuesta hablar con } \\
\text { desconocidos }\end{array}$ & & & & & & & & & & \\
\hline Menores de 30 & 5.85 & 3.01 & $\mathbf{5 . 6 7}$ & 3.08 & $\mathbf{5 . 9 3}$ & 3.10 & $\mathrm{M}$ & 1.34 & .256 & .043 \\
\hline Mayores de 30 & 5.50 & 3.03 & $\mathbf{4 . 6 7}$ & 2.92 & $\mathbf{7 . 0 0}$ & 2.92 & $\mathrm{E}$ & 0.00 & .975 & .000 \\
\hline Total & 5.71 & 2.98 & $\mathbf{5 . 0 7}$ & 2.92 & $\mathbf{6 . 2 1}$ & 3.01 & $\mathrm{M}$ x E & 0.86 & .363 & .028 \\
\hline $\begin{array}{l}\text { 27. Tengo muchos } \\
\text { amigos }\end{array}$ & & & & & & & & & & \\
\hline Menores de 30 & 6.25 & 2.20 & $\mathbf{4 . 8 3}$ & 2.56 & $\mathbf{6 . 8 6}$ & 1.79 & $\mathrm{M}$ & 6.16 & $.019 *$ & .170 \\
\hline Mayores de 30 & 5.71 & 2.09 & $\mathbf{5 . 1 1}$ & 2.32 & $\mathbf{6 . 8 0}$ & 1.10 & $\mathrm{E}$ & 0.02 & .884 & .001 \\
\hline Total & 6.03 & 2.14 & $\mathbf{5 . 0 0}$ & 2.33 & $\mathbf{6 . 8 4}$ & 1.61 & $\mathrm{M} \times \mathrm{E}$ & 0.05 & .824 & .002 \\
\hline
\end{tabular}

Rango escala 0-9 (Mín. 0, Máx. 9, punto medio 5.00); $\mathrm{M}=$ Maltrato; E = Edad; M x E = Maltrato x Edad; FV = Fuentes de variación; $g l=3,30 ; *$ Significativa al $5 \%$ o superior.

De nuevo, el efecto principal de la edad no resultó estadísticamente significativo ( $p$ $>$.05). Hacer amigos con facilidad; ser personas amigables; tener dificultad para hacer amigos; ser personas alegres; experimentar dificultad para hablar con desconocidos; $y$ tener muchos amigos fueron aspectos del autoconcepto social valorados de forma similar tanto por las mujeres menores de 30 años como por las mayores de 30 años de ambos grupos de participantes. El efecto de la interacción (Maltrato x Edad) tampoco alcanzó significación estadística, lo que sugiere que, independientemente del grupo de edad, el establecimiento y mantenimiento de relaciones sociales por parte de las mujeres maltratadas y no maltratadas no difería en función de la edad $(p>.05)$.

\section{c) Dimensión emocional}

El autoconcepto emocional, entendido como la percepción de bienestar y el grado de compromiso en actividades de la vida cotidiana, difería en algunos aspectos entre las mujeres con y sin historia de maltrato. Según se deduce de las puntuaciones medias y de sus respectivos contrastes (Tabla 3), las mujeres que han sufrido maltrato se ponen nerviosas cuando les pregunta un superior (Ítem 23) en grado significativo mayor que las que no lo han sufrido $(M=6.87 \mathrm{vs} . M=3.79)$, siendo estas diferencias estadísticamente significativas $(F=14.59, p=.001)$. También experimentan estados de nerviosismo (Ítem 28) más frecuentemente que las no maltratadas $(M=6.87 \mathrm{vs} . M=3.21)$, siendo el efecto del maltrato estadísticamente significativo $(F=13.33, p=.001)$. 
Estudios Pedagógicos XLVI Nº 2: 421-445, 2020

AUTOCONCEPTO DE MUJERES MIGRANTES MALTRATADAS VÍCTIMAS DE VIOLENCIA MACHISTA: UNA

PROPUESTA EDUCATIVA PARA AYUDAR A RECUPERAR EL EQUILIBRIO EMOCIONAL A TRAVÉS DE LA DANZA

Tabla 3. Dimensión emocional del auto-concepto según historia de maltrato y grupo de edad: comparación de medias por ítem (ANOVA 2 x 2)

\begin{tabular}{|c|c|c|c|c|c|c|c|c|c|c|}
\hline & To & tal & Maltr & tadas & No ma & atadas & & & & \\
\hline Emocional & $M$ & $D T$ & $M$ & $D T$ & $M$ & $D T$ & $F V$ & $\boldsymbol{F}$ & $p$ & Eta \\
\hline $\begin{array}{l}\text { 3. Tengo miedo de } \\
\text { algunas cosas }\end{array}$ & & & & & & & & & & \\
\hline Menores de 30 & 6.10 & 2.87 & 5.83 & 3.25 & 6.21 & 2.78 & M & 1.55 & .222 & .049 \\
\hline Mayores de 30 & 5.71 & 3.02 & 4.89 & 3.22 & 7.20 & 2.17 & $\mathrm{E}$ & 0.00 & .985 & .000 \\
\hline Total & 5.94 & 2.85 & 5.27 & 3.15 & 6.47 & 2.61 & $M \times E$ & 0.80 & .379 & .026 \\
\hline $\begin{array}{l}\text { 8. Muchas cosas } \\
\text { ponen nerviosa }\end{array}$ & & & & & & & & & & \\
\hline Menores de 30 & 5.50 & 2.35 & 6.00 & 2.45 & 5.29 & 2.37 & M & 2.95 & .096 & .090 \\
\hline Mayores de 30 & 6.07 & 2.50 & 6.89 & 1.90 & 4.60 & 2.97 & E & 0.01 & .908 & .000 \\
\hline Total & 5.74 & 2.39 & 6.53 & 2.10 & 5.11 & 2.47 & $M \times E$ & 0.81 & .375 & .026 \\
\hline $\begin{array}{l}\text { 13. Me asusto con } \\
\text { facilidad }\end{array}$ & & & & & & & & & & \\
\hline Menores de 30 & 4.30 & 2.49 & 5.00 & 3.52 & 4.00 & 2.00 & M & 4.12 & .051 & .121 \\
\hline Mayores de 30 & 6.11 & 3.16 & 7.22 & 2.77 & 4.20 & 3.11 & E & 1.49 & .231 & .047 \\
\hline Total & 5.06 & 2.89 & 6.33 & 3.18 & 4.05 & 2.25 & $M \times E$ & 1.04 & .315 & .034 \\
\hline $\begin{array}{l}\text { 18. Cuando me di } \\
\text { algo me pongo m } \\
\text { nerviosa }\end{array}$ & & & & & & & & & & \\
\hline Menores de 30 & 3.75 & 2.97 & 3.50 & 3.33 & 3.86 & 2.93 & M & 0.28 & .600 & .009 \\
\hline Mayores de 30 & 4.57 & 2.77 & 5.11 & 3.06 & 3.60 & 2.07 & $\mathrm{E}$ & 0.39 & .539 & .013 \\
\hline Total & 4.09 & 2.87 & 4.47 & 3.16 & 3.79 & 2.68 & $\mathrm{M} \times \mathrm{E}$ & 0.73 & .398 & .024 \\
\hline $\begin{array}{l}\text { 23. Me pongo nerv } \\
\text { si me pregunta un } \\
\text { superior }\end{array}$ & & & & & & & & & & \\
\hline Menores de 30 & 4.85 & 2.80 & 7.00 & 2.68 & 3.93 & 2.37 & M & 14.59 & $.001 *$ & .327 \\
\hline Mayores de 30 & 5.57 & 2.53 & 6.78 & 1.56 & 3.40 & 2.61 & E & 0.20 & .660 & .007 \\
\hline Total & 5.15 & 2.68 & 6.87 & 1.99 & 3.79 & 2.37 & $M \times E$ & 0.03 & .857 & .001 \\
\hline 28. Me siento ner & & & & & & & & & & \\
\hline Menores de 30 & 3.85 & 2.99 & 5.83 & 3.54 & 3.00 & 2.35 & M & 13.33 & $.001 *$ & .308 \\
\hline Mayores de 30 & 6.21 & 2.61 & 7.56 & 1.33 & 3.80 & 2.68 & $\mathrm{E}$ & 1.95 & .172 & .061 \\
\hline Total & 4.82 & 3.03 & 6.87 & 2.50 & 3.21 & 2.39 & $M \times E$ & 0.26 & .613 & .009 \\
\hline
\end{tabular}

Rango escala 0-9 (Mín. 0, Máx. 9, punto medio 5.00); $\mathrm{M}=$ Maltrato; E = Edad; $\mathrm{M}$ x E = Maltrato x Edad; FV = Fuentes de variación; $g l=3,30 ; *$ Significativa al $5 \%$ o superior. 
Ni el efecto principal de la edad ni el de la interacción (Maltrato x Edad) alcanzaron significación estadística $(p>.05)$, sugiriendo que la percepción del estado emocional y el grado de compromiso en actividades de la vida cotidiana de las mujeres no difería en función de la edad (ser menores o mayores de 30 años) en ninguno de ambos grupos de mujeres. A pesar de esto, las mujeres víctimas de violencia machista $(M=6.33$ vs. $M=$ 4.05), particularmente las mayores de 30 años $(M=7.22, D T=2.77)$, percibían que se asustaban con facilidad en mayor medida que las mujeres no víctimas de maltrato del mismo grupo de edad $(M=4.20, D T=3.11)$; no obstante, dichas diferencias resultaron estadísticamente significativas sólo al $10 \%$ de probabilidad.

\section{d) Dimensión familiar}

Según puede apreciarse en los datos contenidos en la Tabla 4, el maltrato afecta a la implicación, participación e integración en el medio familiar de las mujeres que han sido objeto de maltrato, siendo su efecto principal altamente significativo $(p<.01)$. Así, el grupo de mujeres maltratadas indicaba ser más criticado en casa $(M=5.27$ vs. $M=2.16 ; F=9.90$, $p=.004)$, sentirse menos felices $(M=5.67$ vs. $M=8.53 ; F=13.13, p=.001)$, así como percibían más decepción de sus familias hacia ellas $(M=4.87 v s . M=1.68 ; F=8.32, p=.007)$ que el grupo de las no habían sido maltratadas. Igualmente, esperaban recibir menos ayuda de su familia $(M=4.27$ vs. $M=8.32 ; F=19.32, p=.000)$, menos muestras de confianza de sus padres $(M=5.33$ vs. $M=8.00 ; F=6.55, p=.016)$ y se sentían menos queridas $(M=6.13$ vs. $M=8.42 ; F=6.95, p=.013)$ que las mujeres que no han sufrido maltrato.

Tabla 4. Dimensión familiar del auto-concepto según historia de maltrato y grupo de edad: comparación de medias por ítem (ANOVA 2 x 2)

\begin{tabular}{|c|c|c|c|c|c|c|c|c|c|c|}
\hline \multirow[b]{2}{*}{ Familiar } & \multicolumn{2}{|c|}{ Total } & \multicolumn{2}{|c|}{ Maltratadas } & \multicolumn{2}{|c|}{ No maltratadas } & \multirow[b]{2}{*}{$F V$} & \multirow[b]{2}{*}{$F$} & \multirow[b]{2}{*}{$p$} & \multirow[b]{2}{*}{ Eta } \\
\hline & $M$ & $D T$ & $M$ & $D T$ & $M$ & $D T$ & & & & \\
\hline \multicolumn{11}{|c|}{$\begin{array}{l}\text { 4. Soy muy criticada en } \\
\text { casa }\end{array}$} \\
\hline Menores de 30 & 2.35 & 2.03 & 4.50 & 2.51 & 1.43 & 0.76 & M & 9.90 & $.004 *$ & .248 \\
\hline Mayores de 30 & 5.21 & 2.61 & 5.79 & 2.59 & 4.20 & 2.59 & E & 7.51 & $.010^{*}$ & .200 \\
\hline Total & 3.53 & 2.66 & 5.27 & 2.55 & 2.16 & 1.86 & $M \times E$ & 1.02 & .320 & .033 \\
\hline \multicolumn{11}{|l|}{$\begin{array}{l}\text { 9. Me siento feliz } \\
\text { en casa }\end{array}$} \\
\hline Menores de 30 & 7.75 & 2.12 & 5.83 & 2.99 & 8.57 & 0.85 & M & 13.13 & $.001 *$ & .304 \\
\hline Mayores de 30 & 6.57 & 2.74 & 5.56 & 3.01 & 8.40 & 0.89 & E & 0.09 & .773 & .003 \\
\hline Total & 7.26 & 2.45 & 5.67 & 2.90 & 8.53 & 0.87 & $\mathrm{M} \times \mathrm{E}$ & 0.01 & .945 & .000 \\
\hline \multicolumn{11}{|c|}{$\begin{array}{l}\text { 14. Mi familia está } \\
\text { decepcionada de mí }\end{array}$} \\
\hline Menores de 30 & 2.05 & 2.14 & 3.83 & 3.19 & 1.29 & 0.83 & M & 8.32 & $.007 *$ & .217 \\
\hline Mayores de 30 & 4.57 & 3.39 & 5.56 & 3.32 & 2.80 & 3.03 & $\mathrm{E}$ & 3.10 & .089 & .094 \\
\hline Total & 3.09 & 2.96 & 4.87 & 3.27 & 1.68 & 1.73 & $M \times E$ & 0.01 & .911 & .000 \\
\hline
\end{tabular}


Estudios Pedagógicos XLVI N² 2: 421-445, 2020

AUTOCONCEPTO DE MUJERES MIGRANTES MALTRATADAS VÍCTIMAS DE VIOLENCIA MACHISTA: UNA

PROPUESTA EDUCATIVA PARA AYUDAR A RECUPERAR EL EQUILIBRIO EMOCIONAL A TRAVÉS DE LA DANZA

\begin{tabular}{|l|c|c|c|c|c|c|c|c|c|c|}
\hline $\begin{array}{l}\text { 19. Mi familia me } \\
\text { ayudaría ante cualquier } \\
\text { problema }\end{array}$ & & & & & & & & & & \\
\hline Menores de 30 & 7.75 & 2.10 & $\mathbf{5 . 5 0}$ & 2.59 & $\mathbf{8 . 7 1}$ & 0.73 & $\mathrm{M}$ & 19.32 & $.000^{*}$ & .392 \\
\hline Mayores de 30 & 4.79 & 3.31 & $\mathbf{3 . 4 4}$ & 3.17 & $\mathbf{7 . 2 0}$ & 2.05 & $\mathrm{E}$ & 5.07 & $.032^{*}$ & .144 \\
\hline Total & 6.53 & 3.01 & $\mathbf{4 . 2 7}$ & 3.04 & $\mathbf{8 . 3 2}$ & 1.34 & $\mathrm{M}$ x E & 0.12 & .735 & .004 \\
\hline $\begin{array}{l}\text { 24. Mis padres me dan } \\
\text { confianza }\end{array}$ & & & & & & & & & & \\
\hline Menores de 30 & 7.90 & 1.99 & $\mathbf{6 . 5 0}$ & 2.74 & $\mathbf{8 . 5 0}$ & 1.29 & $\mathrm{M}$ & 6.55 & $.016^{*}$ & .179 \\
\hline Mayores de 30 & 5.29 & 2.64 & $\mathbf{4 . 5 6}$ & 2.65 & $\mathbf{6 . 6 0}$ & 2.30 & $\mathrm{E}$ & 5.92 & $.021^{*}$ & .165 \\
\hline Total & 6.82 & 2.60 & $\mathbf{5 . 3 3}$ & 2.77 & $\mathbf{8 . 0 0}$ & 1.76 & $\mathrm{M}$ x E & 0.00 & .978 & .000 \\
\hline $\begin{array}{l}\text { 29. Me siento querida } \\
\text { por mis padres }\end{array}$ & & & & & & & & & & \\
\hline Menores de 30 & 8.05 & 1.50 & $\mathbf{6 . 8 3}$ & 1.60 & $\mathbf{8 . 5 7}$ & 1.16 & $\mathrm{M}$ & 6.95 & $.013^{*}$ & .188 \\
\hline Mayores de 30 & 6.50 & 3.01 & $\mathbf{5 . 6 7}$ & 3.46 & $\mathbf{8 . 0 0}$ & 1.00 & $\mathrm{E}$ & 1.27 & .269 & .041 \\
\hline Total & 7.41 & 2.34 & $\mathbf{6 . 1 3}$ & 2.85 & $\mathbf{8 . 4 2}$ & 1.12 & $\mathrm{M}$ x E & 0.15 & .703 & .005 \\
\hline
\end{tabular}

Rango escala 0-9 (Mín. 0, Máx. 9, punto medio 5.00); $\mathrm{M}=$ Maltrato; E = Edad; M x E = Maltrato x Edad; FV = Fuentes de variación; $g l=3,30 ; *$ Significativa al $5 \%$ o superior.

El efecto principal de la edad también resultó significativo $(p<.05)$, de modo que las mujeres mayores de 30 años percibían ser más criticada en casa $(p=.010)$ que las menores de 30 años. Igualmente, las mayores de 30 años esperaban recibir menos ayuda de su familia ante cualquier evento problemático $(p=.032)$ y percibían que sus padres desconfiaban más de ellas que las menores de 30 años $(p=.021)$. El efecto de la interacción (Maltrato x Edad) no resultó estadísticamente significativo en ninguno de los componentes del autoconcepto familiar $(p>.05)$, indicando que el grado de integración en la familia de ambos grupos de mujeres no se veía afectado de forma significativa por la edad.

\section{e) Dimensión física}

La percepción del aspecto y condición física de las participantes, tal como se deduce de los datos contenidos en la Tabla 5, se halla influida por la experiencia de maltrato. La vivencia de maltrato influye significativamente en su cuidado físico $(F=8.32, p=$ $.007)$, en aceptarse y gustarse como son físicamente $(F=11.72, p=.002)$, en el grado de participación en actividades deportivas $(F=10.96, p=.002)$, así como en su percepción como buenas deportistas $(F=4.22, p=.049)$. Así, las mujeres víctimas de maltrato se cuidaban significativamente menos que las no maltratadas $(M=5.47 \mathrm{vs} . M=7.74)$, se gustaban menos físicamente $(M=4.87$ vs. $M=7.21)$ y percibían que eran menos requeridas para hacer deporte $(M=4.53 \mathrm{vs} . M=7.05)$ que las que no habían sido maltratadas. Sin embargo, la historia de maltrato no afecta a que se perciban elegantes $(p>.05)$ y atractivas $(p>.05)$ como cualquier otra mujer. 
AUTOCONCEPTO DE MUJERES MIGRANTES MALTRATADAS VÍCTIMAS DE VIOLENCIA MACHISTA: UNA PROPUESTA EDUCATIVA PARA AYUDAR A RECUPERAR EL EQUILIBRIO EMOCIONAL A TRAVÉS DE LA DANZA

Tabla 5. Dimensión física del auto-concepto según historia de maltrato y grupo de edad: comparación de medias por ítem (ANOVA 2 x 2)

\begin{tabular}{|c|c|c|c|c|c|c|c|c|c|c|}
\hline \multirow[b]{2}{*}{ Física } & \multicolumn{2}{|c|}{ Total } & \multicolumn{2}{|c|}{ Maltratadas } & \multicolumn{2}{|c|}{ No maltratadas } & \multirow[b]{2}{*}{$F V$} & \multirow[b]{2}{*}{$\boldsymbol{F}$} & \multirow[b]{2}{*}{$p$} & \multirow[b]{2}{*}{ Eta } \\
\hline & $M$ & $D T$ & $M$ & $D T$ & $M$ & $D T$ & & & & \\
\hline \multicolumn{11}{|c|}{ 5. Me cuido físicamente } \\
\hline Menores de 30 & 7.00 & 2.45 & 4.83 & 3.60 & 7.93 & 0.83 & M & 8.32 & $.007 *$ & .217 \\
\hline Mayores de 30 & 6.36 & 2.13 & 5.89 & 2.52 & 7.20 & 0.84 & $\mathrm{E}$ & 0.05 & .832 & .002 \\
\hline Total & 6.74 & 2.31 & 5.47 & 2.92 & 7.74 & 0.87 & $\mathrm{M} \times \mathrm{E}$ & 1.36 & .252 & .043 \\
\hline \multicolumn{11}{|c|}{$\begin{array}{l}\text { 10. Me buscan para las } \\
\text { actividades deportivas }\end{array}$} \\
\hline Menores de 30 & 6.15 & 2.37 & 4.00 & 3.03 & 7.07 & 1.27 & M & 10.96 & $.002 *$ & .268 \\
\hline Mayores de 30 & 5.64 & 2.50 & 4.89 & 2.57 & 7.00 & 1.87 & $\mathrm{E}$ & 0.27 & .605 & .009 \\
\hline Total & 5.94 & 2.40 & 4.53 & 2.70 & 7.05 & 1.39 & $\mathrm{M} \times \mathrm{E}$ & 0.38 & .544 & .012 \\
\hline \multicolumn{11}{|l|}{$\begin{array}{l}\text { 15. Me considero } \\
\text { elegante }\end{array}$} \\
\hline Menores de 30 & 6.30 & 2.25 & 5.33 & 3.50 & 6.71 & 1.44 & M & 3.54 & .070 & .106 \\
\hline Mayores de 30 & 5.07 & 2.90 & 4.33 & 3.28 & 6.40 & 1.52 & E & 0.52 & .479 & .017 \\
\hline Total & 5.79 & 2.57 & 4.73 & 3.28 & 6.63 & 1.42 & $M \times E$ & 0.14 & .711 & .005 \\
\hline \multicolumn{11}{|c|}{$\begin{array}{l}\text { 20. Me gusta como soy } \\
\text { físicamente }\end{array}$} \\
\hline Menores de 30 & 6.35 & 2.18 & 4.33 & 2.81 & 7.21 & 1.12 & $\mathrm{M}$ & 11.72 & $.002 *$ & .281 \\
\hline Mayores de 30 & 5.93 & 2.27 & 5.22 & 2.54 & 7.20 & 0.84 & $\mathrm{E}$ & 0.38 & .542 & .012 \\
\hline Total & 6.18 & 2.20 & 4.87 & 2.59 & 7.21 & 1.03 & $M \times E$ & 0.41 & .529 & .013 \\
\hline \multicolumn{11}{|c|}{$\begin{array}{l}\text { 25. Soy buena haciendo } \\
\text { deporte }\end{array}$} \\
\hline Menores de 30 & 7.05 & 2.46 & 6.00 & 3.95 & 7.50 & 1.45 & $\mathrm{M}$ & 4.22 & $.049 *$ & .123 \\
\hline Mayores de 30 & 6.86 & 1.83 & 6.22 & 1.86 & 8.00 & 1.23 & $\mathrm{E}$ & 0.21 & .654 & .007 \\
\hline Total & 6.97 & 2.20 & 6.13 & 2.75 & 7.63 & 1.38 & $\mathrm{M} \times \mathrm{E}$ & 0.03 & .863 & .001 \\
\hline \multicolumn{11}{|c|}{$\begin{array}{l}\text { 30. Soy una persona } \\
\text { atractiva }\end{array}$} \\
\hline Menores de 30 & 6.25 & 2.34 & 5.33 & 3.50 & 6.64 & 1.65 & M & 2.63 & .115 & .081 \\
\hline Mayores de 30 & 5.79 & 2.55 & 5.22 & 3.07 & 6.80 & 0.45 & $\mathrm{E}$ & 0.00 & .980 & .000 \\
\hline Total & 6.06 & 2.40 & 5.27 & 3.13 & 6.68 & 1.42 & $M \times E$ & 0.02 & .881 & .001 \\
\hline
\end{tabular}

Rango escala 0-9 (Mín. 0, Máx. 9, punto medio 5.00); $\mathrm{M}=$ Maltrato; $\mathrm{E}=$ Edad; $\mathrm{M}$ x E = Maltrato x Edad; FV = Fuentes de variación; $g l=3,30$; *Significativa al $5 \%$ o superior.

Ni la edad, ni el efecto interactivo de ésta con el maltrato influye en el autoconcepto físico, lo que indica que la percepción de la condición física de mujeres, maltratadas y no maltratadas, es la misma antes que después de los 30 años; es decir, no cambia significativamente con la edad. Con todo, y a pesar de esto, las mujeres que han sido víctimas de maltrato menores de 30 años se cuidan físicamente menos que las mayores de 
$30(M=4.83$ vs. $M=5.89)$ y también se gustan menos físicamente $(M=4.33$ vs. $M=5.22)$ que las que han sufrido maltrato de más de 30 años, a pesar de no resultar significativa esta diferencia.

Partiendo de la hipótesis de que la danza puede ayudar a restablecer los aspectos dañados del bienestar personal y la autoestima, seguidamente se presenta una propuesta que pretende ayudar a mejorar el bienestar psicológico y la estabilidad de las mujeres víctimas de maltrato machista.

\subsection{PLAN DE MEJORA DEL AUTOCONCEPTO A TRAVÉS DE LA DANZA}

Como sugieren las valoraciones realizadas del autoconcepto en sus facetas laboral, social, emocional, familiar y física, las mujeres víctimas de la violencia de género no suelen disponer de un espacio seguro ni de tiempo para la atención y cuidado de su cuerpo y de su estado mental, entendiendo cuerpo y mente como una unidad en la que se albergan todas sus vivencias y desde donde las personas actúan para relacionarse con el exterior. Tampoco suelen disponer de tiempo y espacio para mantener las relaciones socio-laborales y familiares tras el suceso traumático que conlleva la vivencia de maltrato. Como apoyo a su asistencia y ayuda personal, al menos en el tiempo de tránsito por la Casa de Acogida, se propone el programa de intervención que se delinea a continuación. Su propósito es fortalecer el autoconcepto y la percepción de sí mismas para hacer frente a la adversidad con garantías de éxito y recursos propios.

La participación en el programa es de carácter voluntario, respetando así la libertad de las mujeres a incorporarse al mismo. Las actividades se diseñan para ser llevadas a cabo unas veces de forma individual y otras en pareja o en pequeño grupo al objeto de reforzar las relaciones personales y sociales. Se organiza en forma de taller y pensando en la posibilidad de que cuando las participantes hayan adquirido confianza, puedan ser incorporados sus hijos al programa, lo que reforzará su relación materno-filial y facilitará el análisis de sus relaciones y la ayuda que puedan necesitar ambas partes.

Los contenidos del programa se agrupan en cinco unidades, distribuidas en 20 sesiones, focalizadas en las cinco dimensiones del autoconcepto que incluyen los siguientes elementos:

- Autoconcepto físico: el conocimiento corporal y sus posibilidades de movimiento, la toma de conciencia corporal y la aceptación del propio cuerpo tal y como es, el reconocimiento del estado corporal y mental, la atención dirigida hacia cuerpomente y hacia el entorno cercano, la práctica de la respiración, la alineación corporal, el conocimiento del ritmo corporal y temporal.

- Autoconcepto emocional: la relación cuerpo-mente y el estado de bienestar, la visualización guiada, el reconocimiento de las emociones, la canalización de la expresión de las emociones, las diversas manifiestaciones de las emociones en el cuerpo, la exploración de la liberación emocional y la regulación de la energía.

- Autoconcepto familiar: la introducción al contacto, el contacto y su aplicación cuerpo a cuerpo, la creación de una composición entre madre e hijos.

- Autoconcepto social: el conocimiento del espacio propio, el uso del espacio cercano y el espacio compartido, el espacio social, la introducción a la improvisación y a la composición grupal. 
- Autoconcepto laboral: la atención guiada y la concentración, la toma de decisiones en la improvisación pautada, la memorización del material propuesto, la introducción a la creación y construcción de composiciones, la representación de escenas ante personas ajenas, la adquisición de estrategias para presentar y defender una composición ante un público.

Su duración se estima en seis meses, que es el tiempo que suele transcurrir entre la entrada y la salida de una casa de acogida, siendo la frecuencia de implementación de dos sesiones semanales de una hora aproximadamente cada una.

El programa ha sido pensado para que las actividades sean llevadas a cabo por personal especializado en pedagogía de la danza. Desde el primer día, se tratará de crear un ambiente de respeto, confianza y de intercambio de opiniones. Se deben plantear actividades que ofrezcan la posibilidad de relacionarse entre ellas de forma saludable, confiando y respetándose a sí mismas e igualmente a otras personas. Se potenciará, a su vez, la capacidad de comunicación al objeto de que aprendan a expresar lo que necesitan, lo que quieren y lo que no quieren en sus vidas. En cada sesión será conveniente ofrecer un espacio para la reflexión, a modo de feedback, en donde cada participante pueda ir incorporando los comentarios positivos recibidos por parte del grupo y de esta forma consigan valorarse y sentirse personas capaces y valiosas. Se fomentará el reconocimiento de relaciones de dependencia para así evitar los chantajes emocionales y se facilitará la expresión y escenificación de situaciones en las que aparezca el chantaje emocional con el objetivo de aprender a detectarlo y tratar de evitar así el agotamiento emocional y la consecuente debilitación de la autoestima.

Finalmente, una evaluación pretest-postest con medidas repetidas contribuirá a explorar el impacto del programa en las participantes y la consecuente conveniencia de introducir cambios y/o mejoras para maximizar su potencial reparador del bienestar psicológico en función de las valoraciones e indicadores de satisfacción de las participantes.

\section{DISCUSIÓN E IMPLICACIONES}

Este estudio exploró el autoconcepto de un grupo de mujeres víctimas de violencia machista residentes en una Casa de Acogida de la Comunidad Valenciana, España, con la finalidad de detectar la ayuda que precisaban y proponer una iniciativa (programa-taller) para abordar la recuperación del equilibrio emocional perdido. Los resultados revelan que, independientemente de la edad, la experiencia de maltrato afecta al autoconcepto de estas mujeres, el cual se ve debilitado en todas sus dimensiones. Estos hallazgos concuerdan con el estado de baja autoestima y deterioro emocional que caracteriza a estas mujeres identificado en la literatura (Echeburúa, 2004; OMS, 2013; OPS, 2003; Vives Cases et al., 2009), quienes acuden a las Casas de Acogida con la idea de huir de sus agresores y recibir ayuda para emprender una nueva vida.

Los hallazgos aportan evidencia de que las mujeres participantes víctimas de maltrato tienen su autoconcepto laboral distorsionado debido a las experiencias vividas. A pesar de considerarse buenas trabajadoras, no perciben que obtengan un resultado de calidad en los trabajos que realizan, ni que destaquen en ellos. Creen que sus superiores las estiman y las consideran buenas profesionales e inteligentes a un nivel medio, pero no se sienten reconocidas en su trabajo como se merecen. 
Estudios Pedagógicos XLVI N²: 421-445, 2020

AUTOCONCEPTO DE MUJERES MIGRANTES MALTRATADAS VÍCTIMAS DE VIOLENCIA MACHISTA: UNA

PROPUESTA EDUCATIVA PARA AYUDAR A RECUPERAR EL EQUILIBRIO EMOCIONAL A TRAVÉS DE LA DANZA

A nivel social, se perciben, en general, como personas amigables y alegres; no obstante, encuentran dificultad a la hora de hacer amigos, hablar con desconocidos y mantener las amistades, que generalmente son pocas. Estas percepciones son similares tanto en las mujeres menores de 30 como en las mayores de 30 años.

La faceta emocional de su autoconcepto también se encuentra dañada o desequilibrada. Debido a su inseguridad, son muchas las cosas que les ponen nerviosas, pudiendo llegar a alcanzar un nivel alto de nerviosismo y descontrol, particularmente, cuando les pregunta un superior.

En relación a la dimensión familiar, a pesar de reconocer ser objeto de críticas en el seno familiar algunas decían sentirse felices, lo que ofrece solo apoyo parcial a la opinión experta (e.g., OPS, 2003, 2013; OMS, 2013; Vives Cases et al., 2009) que las describe más bien como personas infelices e inestables. Asimismo, de forma significativa, las mayores de 30 años indicaban que sus padres no les daban la confianza necesaria ni se sentían suficientemente queridas por ellos. Por lo tanto, se puede concluir que, en esta dimensión, las mujeres que han sufrido maltrato mayores de 30 años tienen más difícil su integración y comprensión familiar que las menores de 30 años.

Por último, el estudio reveló que la mayoría de las participantes con historia de maltrato poseen un bajo autoconcepto en lo que se refiere a su aspecto y condición física. La investigación ha puesto de relieve que las mujeres maltratadas en comparación con las que no han sufrido maltrato se cuidan de forma insuficiente y se gustan físicamente menos que éstas, con independencia de la edad.

Por todo lo anterior, las mujeres que han sido víctimas de maltrato machista necesitan recuperar el equilibrio emocional y bienestar psicológico a través del fortalecimiento de su autoconcepto profesional, socioemocional, familiar y físico. La danza contemporánea ofrece la oportunidad de crear ambientes para fortalecerlo y desarrollarlo no solo en ellas, sino también en sus hijos. El programa delineado tiene el potencial de contribuir a empoderarlas ayudándoles a asimilar y comprender mejor la realidad mediante una intervención integral que abarque la dimensión cognoscitiva, afectiva y axiológica. Según Leventhal (1980), la danza favorece el desarrollo emocional y la afectividad restaurando la comunicación con el medio y con otras personas, tanto de forma verbal como a través de la expresión corporal, el ritmo, el movimiento y la música. A través de la implementación del programa, se podrá aportar conocimiento acerca de la gestión y control de sus emociones, redefinir el espacio personal invadido sin permiso, a menudo, en estos casos, y ayudar a superar sus problemas de inhibición al tacto, al incluir progresivamente actividades que profundizan en el contacto corporal (Salzer, 1984). Asimismo, con la técnica de improvisación pautada, se guiará a las participantes a que puedan ir tomando decisiones y combatan la falta de iniciativa por bajo autoconcepto o escasa confianza en sí mismas. El programa favorecerá un mayor conocimiento de su cuerpo con la pretensión de que lo cuiden, lo acepten como es y lo disfruten. Además, aportará información sobre sus posibilidades de acción motriz, apoyándose en la utilización de la respiración, la relajación, la visualización de imágenes, así como del reconocimiento de sensaciones y de la improvisación pautada. Por último, otra de las virtualidades del programa es que ayudará a las participantes a conseguir la concentración necesaria para abordar las tareas de su día a día al guiarles mediante actividades de focalización de la atención a liberar la tensión acumulada en sus cuerpos y en sus mentes, utilizar y liberar la energía según sus necesidades, utilizar la danza como medio de expresión de sus emociones, y a lograr un equilibrio emocional que les ayude a gestionar sus vidas adecuadamente. 
Aunque los hallazgos deben ser interpretados con cautela, dado el pequeño tamaño de las muestras y su forma de selección (muestreo disponible), el estudio puede considerarse valioso teniendo en cuenta la insuficiente atención que reciben las mujeres víctimas de violencia de género debido a la escasez presupuestaria de los gobiernos destinada a su ayuda. El hecho de que las mujeres que han sufrido maltrato tengan la oportunidad de participar en talleres de danza similares al propuesto añade valía al estudio, no solamente por su impacto potencial en ellas mismas, sino también en sus hijos. Finalmente, el estudio abre las puertas a una nueva línea de investigación e intervención con las víctimas, madres e hijos de violencia machista, quienes como resultado de su participación en el programa podrán aprender a expresar sus sentimientos y pensamientos, como también a gestionar mejor su vida utilizando sus propios recursos. La aportación de la danza a la educación y fortalecimiento del autoconcepto en mujeres maltratadas y sus efectos en el desempeño emocional, social, profesional y familiar futuro de estas mujeres puede ser crucial para su reinserción a las actividades de la vida ordinaria. Los testimonios de mujeres residentes en la Casa apuntan en ese sentido:

Cuando llegas a la Casa es muy difícil la convivencia, porque todo son normas y venimos de unas situaciones muy difíciles y te encuentras con esto, y entonces parece que te vas a volver loca de estar aquí dentro. Te sientes encerrada, y si antes de entrar en la Casa pensabas que ibas a estar mejor luego te das cuenta de que no es como pensabas. Es muy difícil también la convivencia con las personas que van llegando o que ya están dentro, cada una con sus problemas, con las que a veces no puedes comunicarte porque hablan otros idiomas o porque no quieren relacionarse, ... yo me he sentido muy apoyada por algunas compañeras y también por las trabajadoras de la Casa. (Mailín)

En la casa de acogida gracias al apoyo psicológico que he recibido he aprendido a prestar atención a mis emociones y a tratar de comprender lo que me pasa. (Bonia)

Aquí me han ayudado mucho, me han facilitado lo que necesitaba y puedo empezar de cero, además sé que mi vida va a mejorar. A veces me siento insegura, ...creo que no confío mucho en mí misma. (Cristiane)

\section{REFERENCIAS BIBLIOGRÁFICAS}

Agencia Europea para los Derechos Fundamentales (2014). Violencia de género contra las mujeres: una encuesta a escala de la Unión Europea. Luxemburgo: Oficina de Publicaciones de la Unión Europea.

Bringiotti, M. I. (2000). La escuela ante los niños maltratados. Buenos Aires: Paidós.

Delegación del Gobierno de España para la Violencia de Género (2019). Víctimas mortales por violencia machista. Recuperado de http://www.violenciagenero.igualdad.mpr.gob.es/ laDelegacionInforma/home.htm

Duong, M. T., Schwartz D., Chang L., Kelly, B. M. y Tom, S. R. (2009). Associations between maternal physical discipline and peer victimization among Hong Kong Chinese children: The moderating role of child aggression. Journal of Abnormal Child Psychology, 37(7), 957-966.

Echeburúa, E. (2004. Superar un trauma: el tratamiento de las víctimas de sucesos violentos. Madrid: Pirámide. 
Estudios Pedagógicos XLVI Nº 2: 421-445, 2020

AUTOCONCEPTO DE MUJERES MIGRANTES MALTRATADAS VÍCTIMAS DE VIOLENCIA MACHISTA: UNA

PROPUESTA EDUCATIVA PARA AYUDAR A RECUPERAR EL EQUILIBRIO EMOCIONAL A TRAVÉS DE LA DANZA

Fux, M. (1976). Danza experiencia de vida. Buenos Aires: Paidós.

Gallego, G. (2015). El Convenio de Estambul: su incidencia en el sistema español de lucha frente a la violencia contra la mujer. Recuperado de https://elderecho.com/el-convenio-de-estambul-suincidencia-en-el-sistema-espanol-de-lucha-frente-a-la-violencia-contra-la-mujer

García, F. y Musitu, G. (1999). Test AF5 de Autoconcepto. Madrid: TEA Ediciones.

Instituto Nacional de la Mujer y para la Igualdad de Oportunidades (2018). Denuncias por discriminación por razón de género. Recuperado de http://institutoasturianodelamujer.com/iam/ servicios-2/denuncias-por-discriminacion-por-razon-de-genero/

Instituto Europeo para la Igualdad de Género (IEIG) (2015). Índice de igualdad de género 2015: España. Recuperado de http://eige.europa.eu/publications/gender-equality-index-2015spain\#downloads-wrapper

Larraín, S. y Bascuñan C. (2008). Maltrato infantil y relaciones familiares en Chile: análisis comparativo 1994-2000-2006. Revista Chilena de Pediatrica, 79(1), 64-79.

Leventhal, M. B. (1980). Movement and growth: Dance therapy for special child. New York, NY: Centre for Educational Research, New York University.

Ley Orgánica 1/2004, de 28 de diciembre, de Medidas de Protección Integral contra la Violencia de Género. Boletín Oficial del Estado, 313, de 29 de diciembre.

Ley 7/2012, de 23 de noviembre, de la Generalitat, Integral contra la Violencia sobre la Mujer en el Ámbito de la Comunitat Valenciana. Diario Oficial de la Generalitat Valenciana, 6912, de 28 de noviembre.

Mesa, M. C., Aisa, O. y Letosa, L. (2011). Una mirada hacia los hijos e hijas expuestos a situaciones de violencia de género: orientaciones para la intervención desde los Servicios Sociales en Aragón. Recuperado de https://www.observatoriodelainfancia.es/oia/esp/documentos_ficha. aspx?id=3686

Ministerio de Igualdad, Gobierno de España (2010). Mujeres, infancia y violencia de género: un nuevo enfoque. Madrid: Autor. Recuperado de https://eige.europa.eu/docs/107-ES.pdf

Naciones Unidas (1948). Declaración Universal de los Derechos Humanos. Recuperado de https:// www.un.org/es/universal-declaration-human-rights/

Naciones Unidas (1975). Primera Conferencia Mundial sobre la Mujer. Recuperado de HYPERLINK http://base.d-p-h.info/es/fiches/premierdph/fiche-premierdph-2359.html

Naciones Unidas (1979). Convención sobre la Eliminación de Todas las Formas de Discriminación contra la Mujer (CEDAW). Recuperado dehttp://www.un.org/womenwatch/daw/cedaw/text/ sconvention.htm

Naciones Unidas (1993). Declaración sobre la Eliminación de la Violencia contra la Mujer. (Resolución de la Asamblea General 48/104 del 20 de diciembre de 1993). Recuperado de https:// www.ohchr.org/sp/professionalinterest/pages/violenceagainstwomen.aspx

Naciones Unidas (2006). Derechos del niño: Nota del Secretario General. Recuperado de https:// www.unicef.org/violencestudy/reports/SG_violencestudy_sp.pdf

ONU Mujeres (2018). Informe anual 2017-2018. Recuperado de http://www.unwomen.org/es/digitallibrary/publications/2018/6/annual-report-2017-2018

Organización Mundial de la Salud (OMS) (2013). La OMS destaca que la violencia contra la mujer es "un problema de salud global de proporciones epidémicas". Recuperado de https://www.who.

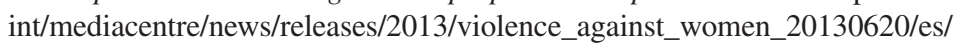

Organización Mundial de la Salud (OMS) (2017). Violencia contra la mujer. Recuperado de https:// www.who.int/es/news-room/fact-sheets/detail/violence-against-women

Organización Panamericana de la Salud (OPS) (2003). La violencia contra las mujeres: responde el sector salud. Recuperado de https://iris.paho.org/handle/10665.2/3273

Organización Panamericana de la Salud (OPS) (2013). Comprender y abordar la violencia contra las mujeres: consecuencias para la salud. Recuperado de https://apps.who.int/iris/bitstream/ handle/10665/98821/WHO_RHR_12.37_spa.pdf?sequence=1\&isAllowed=y 
AUTOCONCEPTO DE MUJERES MIGRANTES MALTRATADAS VÍCTIMAS DE VIOLENCIA MACHISTA: UNA PROPUESTA EDUCATIVA PARA AYUDAR A RECUPERAR EL EQUILIBRIO EMOCIONAL A TRAVÉS DE LA DANZA

Plataforma CEDAW (2014). Informe Sombra: sobre la aplicación en España de la CEDAW. Recuperado de http://www.rednosotrasenelmundo.org/IMG/pdf/InformeSombra_Actualizado_23Sep_2014. pdf

UNIFEM (Fondo de Desarrollo de las Naciones Unidas para la Mujer) (2010). Trabajo de UNIFEM: presupuestos sensibles al género. Recuperado de http://www.unwomen.org//media/headquarters/ media/publications/unifem/evaluation_grb_programme_es.pdf?la=es\&vs=2308

Pastor Bravo, M. (2015). Psiquiatría forense. Alicante: Servicio de Publicaciones de la Universidad de Alicante.

Patró, R. y Limiñana, R. M. (2005). Víctimas de violencia familiar: Consecuencias psicológicas en hijos de mujeres maltratadas. Anales de Psicología, 21(1), 11-17.

Salzer, J. (1984). La expresión corporal. Barcelona: Herder.

Save the Children (2012). En la violencia de género no hay una sola víctima. Recuperado de https:// www.savethechildren.es/sites/default/files/imce/docs/no_hay_una_sola_victima_informe_ euskadi_castellano_vok.pdf

Schwartz, D., McFadyen-Ketchum, S., Dodge, K. A., Pettit, G. S. y Bates, J. E. (1999). Early behavior problems as a predictor of later peer group victimization: Moderators and mediators in the pathways of social risk. Journal of Abnormal Child Psychology, 27(3), 191-201.

Vives Cases, C., Álvarez Dardet, C., Gil González, D., Torrubiano Domínguez, J., Rohlfs, I. y Escribà Agüir, V. (2009). Perfil sociodemográfico de las mujeres afectadas por violencia del compañero íntimo en España. Gaceta Sanitaria, 23(5), 410-414.

WAVE, Women Against Violence Europe (2015). WAVE report 2015: On the role of specialist women's support services in Europe. Recuperado de https://fileserver.wave-network.org/researchreports/ WAVE_Report_2015.pdf 
